\title{
Factors Influencing Crystallization of Erythritol in Aqueous Solutions: A Preliminary Study
}

\author{
Oxana Tyapkova ${ }^{1}$, Stephanie Bader-Mittermaier $^{1} \&$ Ute Schweiggert-Weisz ${ }^{1}$ \\ ${ }^{1}$ Fraunhofer Institute for Process Engineering and Packaging IVV, Freising, Germany \\ Correspondence: Stephanie Mittermaier, Fraunhofer Institute for Process Engineering and Packaging IVV, \\ Giggenhauser Str. 35, Freising D-85354, Germany. Tel: 49-8161-491-412. E-mail: \\ stephanie.mittermaier@ivv.fraunhofer.de
}

\author{
Received: September 7, 2012 Accepted: September 24, 2012 Online Published: October 30, 2012 \\ doi:10.5539/jfr.v1n4p207 URL: http://dx.doi.org/10.5539/jfr.v1n4p207
}

\begin{abstract}
Erythritol - a new zero caloric sweetener - shows high potential for developing new sugar reduced or sugar free food formulations. Since the crystallization behavior of erythritol was not investigated so far, this study focused on factors influencing erythritol crystallization in aqueous solutions using a simple gravimetric method. The general features of the course of crystallization are a linear increase until a period of $2.5 \mathrm{~h}$ of storage followed by a decelerating phase and a phase which represents equilibrium. Additionally, different influencing factors (supersaturation level, storage temperature, storage period and cooling rate) on the crystallization process of erythritol were investigated. It was shown that crystallization value increased with increasing supersaturation level and the progress of crystallization was almost linear from the initial induction period until equilibrium. Therefore, a first-order kinetic for erythritol crystallization was proposed, because only supersaturation level correlated to the erythritol concentration in the solution influenced the course of crystallization. Calculated crystallization rate constants increased considerably with increasing supersaturation levels. Furthermore, at the same supersaturation levels crystallization of erythritol was independent from the storage temperature. Cooling rate influenced only crystal shapes and sizes, but not the crystallization values.
\end{abstract}

Keywords: erythritol, crystallization, kinetic, reaction order, crystal size, rate constant

\section{Introduction}

Erythritol, a representative of the chemical class of polyols, exhibits a sweetness of 60 to $80 \%$ of the sweetness of sucrose (Röper \& Goossens, 1993; Yoon et al., 2003). Generally, erythritol has not been extensively used as sugar replacer since it has just been approved as a bulk sweetener in the European Union in 2008. However, the interest in the utilization of erythritol is steadily growing over the last few years probably due to its calorific value of $0 \mathrm{kcal} \mathrm{g}^{-1}$ according to the European directive on food additives 2008/100/EC. Erythritol is a white, anhydrous, non-hygroscopic, crystalline substance with a sweetening profile quite similar to that of sucrose, but lower intensity and a strong cooling effect, which is due to the negative heat of solution of $-24.1 \mathrm{~kJ} \mathrm{~mol}^{-1}$. In some products this cooling effect is desirable, e.g. in peppermint or menthol flavored products, but it is objectionable in many others such as baked goods and chocolate (Perko \& DeCock, 2006). Until now, few studies have been conducted on the physical, chemical and physiological properties of erythritol in aqueous solutions and highly concentrated melts (Lopes, Nunes, Ramos, Matos, \& Redinha, 2010; Ohmori, Ohno, Makino, \& Kashira, 2004; Perko \& DeCock, 2006). The moderate solubility of erythritol at saturation of about $54 \mathrm{~g}$ per $100 \mathrm{~g}$ water at $20^{\circ} \mathrm{C}$ is much lower than the solubility of sucrose with about $200 \mathrm{~g}$ per $100 \mathrm{~g}$ water (Ohmori et al., 2004; Perko \& DeCock, 2006). In course of the commercial production, erythritol is easily separated by crystallization from a mixture of other polyols with a purity of more than $99 \%$. Facilitating its production, the rapid crystallization is assumed to be one drawback for the application of erythritol in food products.

Plenty of data is available for the crystallization of different sugars, especially sucrose and lactose, including the characterization of crystallization parameters and mathematical approaches for the description of crystallization process during sugar production. These studies have been conducted starting in the early $20^{\text {th }}$ century (Trgo, Koxholt, \& Kessler, 1999; Twieg \& Nickerson, 1968; Van Hook, 1944 \& 1945). The most important influencing factors were found to be temperature, the degree of supersaturation and the viscosity of the sugar containing 
solution. Based on these early researches current studies preliminary deal with the influences of various additives like colloids and impurities rather than crystallization of pure solutions (Abdel-Rahman, Schick, \& Kurz, 2007; Abdel-Rahman, Smejkal, Schick, Ei-Syiad, \& Kurz, 2008; Bhandari \& Hartel, 2002; Martins, Rocha, \& Rein, 2005; Martins et al., 2009).

However, to the best of our knowledge, studies about the factors influencing the course of erythritol crystallization in aqueous solutions as well as mechanistic studies have not been published so far as erythritol is a pretty new polyol used in food industry. Prior to the quantification of erythritol crystallization in binary or ternary solutions as well as simple and complex model food systems, the factors influencing the crystallization behavior in pure aqueous solutions were studied using a simple gravimetric method. Gravimetric measurements of crystallization are sufficient for the purpose of the present preliminary study, because they provide a simple and rapid method for quick analysis. Furthermore using this simple gravimetric method, characteristics of erythritol could be easily analyzed for further application tests in both food and pharmaceutic areas as it was shown by Ohmori et al. (2004).

Thus, the main objectives of the present study were to investigate the influences of various erythritol concentrations, storage temperatures, storage times as well as cooling rates of the solutions on the crystal formation and the amount of crystallization. Furthermore, erythritol crystallization and storage times at various temperatures were correlated to identify kinetics for erythritol crystallization and propose a possible crystallization mechanism. This knowledge contributes to product and process developments in the future; in particular this study might be the basis for a better understanding of erythritol crystallization during production, but also during the storage of food products.

\section{Materials and Methods}

\subsection{Materials}

Crystalline erythritol (purity 99.9\%) was provided by Jungbunzlauer AG, Switzerland.

\subsection{Methods}

\subsubsection{Determination of Erythritol Saturation}

To determine the saturation of erythritol in a wide range of temperatures, saturated erythritol solutions were prepared at $1,5,15,20,30,40,50,60$, and $80^{\circ} \mathrm{C}$, respectively. For this purpose, $15 \mathrm{~g}$ of demineralized water were accurately $( \pm 0.1 \mathrm{mg})$ weighed into a $100 \mathrm{~mL}$ beaker and small amounts of crystalline erythritol were added. In order to dissolve the erythritol crystals, the erythritol solution was stirred constantly at the temperatures of saturation, which have been mentioned above, until complete dissolution. To prevent water evaporation, the beakers were sealed during mixing with a Parafilm $\mathrm{M}^{\mathbb{B}}$ laboratory film. The addition of erythritol crystals was continued until the solution was saturated, meaning the added erythritol crystals remained as sediment on the bottom of the beaker and no further dissolution occurred. Afterwards, the undissolved erythritol crystals were removed by decantation and about $10 \mathrm{~g}$ of clear saturated erythritol solution were accurately $( \pm 0.1 \mathrm{mg})$ weighed into a crystallizing dish for the determination of dry matter. The solution was dried to weight constancy for $24 \mathrm{~h}$ at $80^{\circ} \mathrm{C}$ in a drying oven (Heraeus Instruments, Kendro Laboratory Products GmbH, Germany). Each determination was carried out at least in duplicate. Finally, the saturation ( $\left.100 \mathrm{~g} \mathrm{water}^{-1}\right)$ was calculated using the following equation:

$$
\text { Saturation }\left(\mathrm{g} 100 \mathrm{~g} \mathrm{water}^{-1}\right)=\frac{\mathrm{m}_{\mathrm{dry}} * 100}{\mathrm{~m}_{\text {water }}}=\frac{\mathrm{m}_{\mathrm{dry}} * 100}{\left(\mathrm{~m}_{0, \mathrm{~s}}-\mathrm{m}_{\mathrm{dry}}\right)}
$$

where $\mathrm{m}_{\text {dry }}$ is the weight of dried erythritol in the saturated solution $(\mathrm{g})$ and $\mathrm{m}_{\text {water }}$ is the weight of the water in the saturated solutions calculated by $\left(\mathrm{m}_{0, \mathrm{~s}}-\mathrm{m}_{\text {dry }}\right)(\mathrm{g})$, where $\mathrm{m}_{0, \mathrm{~s}}$ is the amount of saturated solution used for the determination of the dry matter content.

\subsubsection{Preparation of Erythritol Solutions}

According to its saturation, aqueous solutions of various concentrations of erythritol were prepared in order to determine the course of crystallization and its influencing factors. To obtain saturated solutions at 5 to $60^{\circ} \mathrm{C}$,

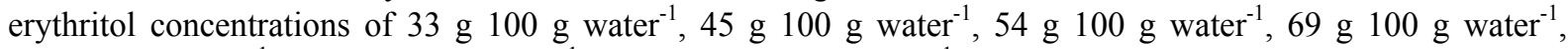
$89 \mathrm{~g} 100 \mathrm{~g} \mathrm{water}^{-1}, 113 \mathrm{~g} 100 \mathrm{~g}$ water $^{-1}$, and $150{\mathrm{~g} 100 \mathrm{~g}^{-1} \text { water }}^{-1}$ were prepared according to the respective saturation. In detail, erythritol crystals were weighed accurately $( \pm 0.1 \mathrm{mg})$ into beakers and dissolved in demineralized water under constant stirring for $30 \mathrm{~min}$ at temperatures of 5 to $60^{\circ} \mathrm{C}$. To prevent water 
evaporation the beakers were sealed with a Parafilm $\mathrm{M}^{\circledR}$ laboratory film. These solutions were used for the determination of erythritol crystallization during the storage of erythritol at different temperatures, concentrations and cooling rates as described below (section 2.2.3).

\subsubsection{Setup of the Storage Experiments}

\subsubsection{Influence of Erythritol Concentration and Storage Time on Crystallization Behavior}

To study the influence of the concentration of erythritol on the course of crystallization, the prepared erythritol solutions containing different concentrations (section 2.2.2) were stored at $5^{\circ} \mathrm{C}$ for $0.5,1,2,24$ and $168 \mathrm{~h}$ (1 week), respectively. After the storage time the samples were directly analyzed for their crystallization values using the gravimetric method described in section 2.2.4. Each experiment was carried out at least in duplicate.

\subsubsection{Influence of Storage Temperature on Crystallization Behavior}

Erythritol solutions containing $113 \mathrm{~g}$ erythritol per $100 \mathrm{~g}$ water were kept at constant temperatures of $5^{\circ} \mathrm{C}$ and $20^{\circ} \mathrm{C}$ to simulate cold storage and storage at ambient temperature, respectively, in order to investigate the influence of storage temperature on the course of crystallization. The solutions were stored as described previously for $0.5 \mathrm{~h}$ to a maximum of $168 \mathrm{~h}$ (1 week). The crystallization values were determined at least in duplicate using the gravimetric method (section 2.2.4).

\subsubsection{Influence of Cooling Rate on Crystallization}

The influence of the cooling rate on the course of erythritol crystallization was investigated using a highly concentrated solution containing $150 \mathrm{~g}$ erythritol per $100 \mathrm{~g}$ water. Immediately after preparation, the erythritol solution was divided into two parts. One aliquot was rapidly cooled to $5^{\circ} \mathrm{C}$ within $10 \mathrm{~min}$ representing a cooling rate of $5.5 \mathrm{~K} \mathrm{~min}^{-1}$, the other aliquot was slowly cooled to $5^{\circ} \mathrm{C}$ within $55 \mathrm{~min}$ corresponding to a cooling rate of $1 \mathrm{~K} \mathrm{~min}{ }^{-1}$. After reaching $5^{\circ} \mathrm{C}$, the solutions were further stored at this temperature for a maximum of $168 \mathrm{~h}$ and the crystallization values were gravimetrically determined after $0.5,1,2,24$ and $168 \mathrm{~h}$, respectively.

After $168 \mathrm{~h}$ of storage, both samples were used for the microscopic analysis of crystal shapes and sizes. Therefore, the crystals were separated from the erythritol solution by decantation and placed in a thin layer on a microscopic slide for further evaluation (section 2.2.5).

\subsubsection{Gravimetric Determination of Crystallization Values}

Crystallization of erythritol from aqueous solutions was determined using the gravimetric method described by Ohmori et al. (2004) with slight modifications. Immediately after storage under defined conditions of the individual erythritol solutions (section 2.2.3), the supernatants containing dissolved erythritol molecules were separated from the erythritol crystals by decantation. In order to remove adhesive moisture, the erythritol crystals were subsequently dried to weight constancy at $80^{\circ} \mathrm{C}$ for $24 \mathrm{~h}$ in a drying oven. The value of crystallization (\%) was calculated using the following equation:

$$
\text { Crystallization }_{\text {grav }}(\%)=\frac{\mathrm{c}_{\text {cryst }} * 100}{\mathrm{c}_{0}}
$$

where $c_{\text {cryst }}$ is the concentration of crystallized erythritol ( $\mathrm{g}$ erythritol crystals per $100 \mathrm{~g}$ water) and $\mathrm{c}_{0}$ is the initial concentration of erythritol (g per $100 \mathrm{~g}$ water).

\subsubsection{Microscopic Analysis of Crystals}

Erythritol crystals were examined using a light-optical microscope (Leitz Diaplan, Ernst Leitz Wetzlar GmbH, Germany) equipped with a video copy processor (model P6IE, Mitsubishi Electric Ltd., Japan). The magnification was hundredfold for all samples using PL Fluotar, 10x lens (Leitz Diaplan) and the size was determined using a relative measurement scale. To obtain the relative size, the micrometer value was determined using a measuring eyepiece equipped with a $10 \mathrm{~mm}$ scale (equivalent to 100 graduation lines). Therefore, at a magnifold of 100 each graduation line equates to $10 \mu \mathrm{m}$.

\subsection{Statistical Analysis}

All determinations were carried out at least in duplicate. Significant differences between crystallization values were analyzed using the Student t-test (Microsoft Excel, 2010, Microsoft Corporation Redmond, USA).

\section{Results and Discussion}

Erythritol shows high potential for the replacement of sugar in various food systems. However, its rapid crystallization constitutes a considerable drawback for its application in food products. Since literature knowledge regarding the crystallization behavior of erythritol is scarce, the impact of the degree of 
supersaturation, storage conditions and cooling rates were investigated and discussed. Prior to these analyses, the saturation of erythritol at specific temperatures was determined to adjust erythritol concentration accurately.

\subsection{Saturation of Erythritol}

The saturation levels of erythritol implicating its maximum solubility were determined at $5^{\circ} \mathrm{C}$ up to $80^{\circ} \mathrm{C}$. The saturation of erythritol amounts to $33 \mathrm{~g}$ per $100 \mathrm{~g}$ water at $5^{\circ} \mathrm{C}$ and increases with higher temperatures. At $20^{\circ} \mathrm{C}$ $54 \mathrm{~g}$ of erythritol crystals were soluble in $100 \mathrm{~g}$ water, while the saturation at $80^{\circ} \mathrm{C}$ amounted to $257 \mathrm{~g}$ erythritol per $100 \mathrm{~g}$ water. The observations of our study confirm the investigations of Perko and DeCock (2006), who reported similar maximal solubilities of erythritol in a temperature range of $10^{\circ} \mathrm{C}$ up to $80^{\circ} \mathrm{C}$. The temperature of $5^{\circ} \mathrm{C}$ applied in our study was chosen, since reduced sugar and sugar-free products might also be retained under cold storage.

\subsection{Kinetic of Erythritol Crystallization from Its Pure Aqueous Solution}

In order to reveal the course of crystallization of erythritol, a saturated erythritol solution containing $69 \mathrm{~g}$ erythritol per $100 \mathrm{~g}$ water was prepared at $30^{\circ} \mathrm{C}$. After preparation, the solution was cooled down to $5^{\circ} \mathrm{C}$ and stored for $0.08,0.25,0.5,1,2,3,5,8$, and $15 \mathrm{~h}$, respectively. The supersaturation level $\mathrm{S}$ of the obtained freshly produced solution amounted to 1.1 . This supersaturation level was calculated using the following equation:

$$
\mathrm{S}=\left(\mathrm{c}(\mathrm{T}) / \mathrm{c}_{\mathrm{s}}\right)-1
$$

where $\mathrm{c}_{\mathrm{s}}$ is the concentration of erythritol saturated at $5^{\circ} \mathrm{C}$ and $20^{\circ} \mathrm{C}$ corresponding to the above mentioned storage temperature and $\mathrm{c}(\mathrm{T})$ is the concentration of saturation depending on the temperature, at which the solution was prepared. Therefore, in the present study $c(T)$ is equal or exceeds the level of $c_{s}$.

The crystallization values after different storage times are shown in Figure 1. Generally, the crystallization process consists of two major events, namely the nucleation and crystal growth. Nucleation is the initial step of crystallization, at which the solute dispersed molecules start to gather into clusters. The clusters need to reach a critical size in order to become a stable nucleus for crystal growth. The critical size of these initial nuclei is determined by operation conditions such as temperature and supersaturation. Subsequently, the crystal growth is the accretion of further solute molecules to the initial nuclei until a critical cluster size is reached and crystals are formed. Both steps occur simultaneously, revealing supersaturation level as the driving force of the crystallization process under the current operation conditions. However, the crystallization is not only influenced by concentration and cooling rate and it is difficult to elucidate the quite complex processes responsible for forming crystals using a single method. According to Figure 1 the crystallization progress of erythritol seemed to consist of 3 different phases, an almost linear gain of crystallization, a transition phase reaching equilibrium and the equilibrium phase of crystalline and solute erythritol. During the first time of storage, extending from $0 \mathrm{~h}$ to $0.5 \mathrm{~h}$, the system balanced in order to achieve a constant temperature of $5^{\circ} \mathrm{C}$. Furthermore, it is most likely that the solute molecules realign to initiate the first nuclei prior to crystal growth. Therefore, no crystallization was determined during this period. A crystallization value of $2 \%$ was found to be the determination limit of the gravimetric method applied for measuring the crystallization, since this crystallization value was already determined at the beginning of the experiment. However, distinct process steps occurring during balancing of erythritol solutions could not be obtained as molecular phenomena were not part of this investigation. These should be addressed in future research. 


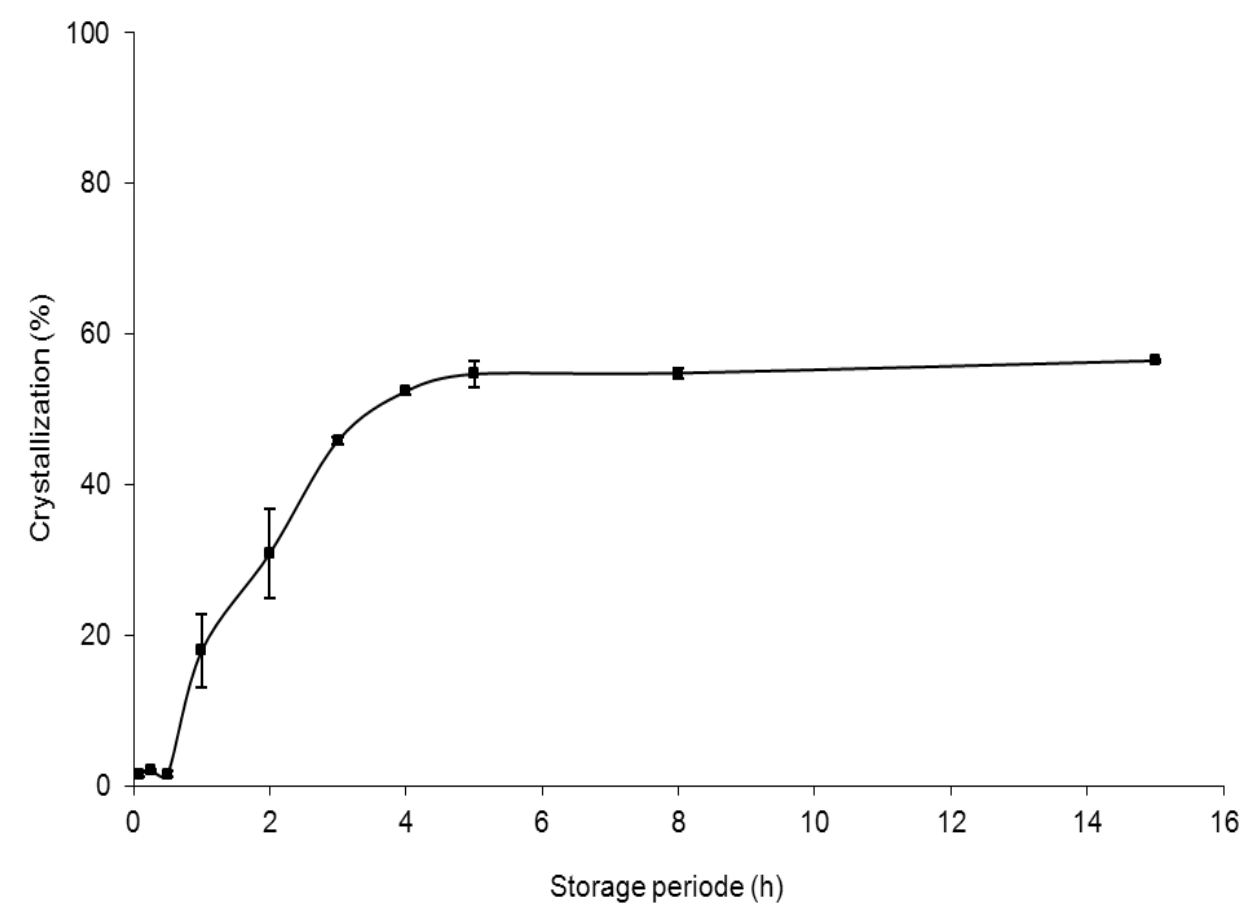

Figure 1. Course of crystallization of erythritol at a concentration of $69 \mathrm{~g}$ erythritol per $100 \mathrm{~g}$ water (supersaturation level $=1.1$ ) stored at $5^{\circ} \mathrm{C}$

In the first phase of erythritol crystallization an almost linear rise of the crystallization values was observed ranging from $2 \%$ up to $46 \%$ within $2.5 \mathrm{~h}$. This course could be attributed to both an increasing nucleation level and a progressive crystal growth. After storage for more than $2.5 \mathrm{~h}$ the extent of crystallization decelerated reaching a maximum of $52 \%$ at $5 \mathrm{~h}$ of storage. During the equilibrium phase in a crystallizing system the crystal formation and growth seemed to stop as a result of equilibrium between soluble and crystalline erythritol was reached. The remaining dissolved erythritol molecules corresponded to the saturation of erythritol at $5^{\circ} \mathrm{C}$. These results are in good agreement with the findings of Van Hook (1944), who described the crystallization of sucrose at $30^{\circ} \mathrm{C}$. In contrast to that study, the initial period prior to crystallization was significantly longer in our study, which may be related to the stirring and the addition of seed crystals in the investigation of Van Hook (1944). Due to the addition of seed crystals, initial nucleation in the case of sucrose (Van Hook, 1944) did not occur and therefore, the process might be driven solely by crystal growth. Quite contrary to those findings, initial nuclei had to be formed from aqueous erythritol solutions (primary nucleation) in our study. Primary nucleation is a time and energy consuming process, which results in delayed increase of crystal formation. In order to clarify the mechanism of the formation of initial nuclei by erythritol, more precise methods like X-ray diffraction, confocal laser scanning microscopy or atomic force spectroscopy should be applied (e.g. Lopes et al., 2010).

The crystal growth, which is the second step during crystallization, is controlled by the level of supersaturation, the area of the crystal surface, the time, as well as flow patterns. For the unstirred crystallization of erythritol in the present study a first-order kinetic can be assumed as only the concentration of erythritol in the solution seemed to influence the crystallization. Additionally, an estimated reaction rate constant will be discussed in detail in section 3.3.

The first diffusion theory according to the Fick's first law was transferred to the crystallization of sugars in aqueous solutions (Campbell \& Campbell, 1937; Van Hook, 1944 \& 1945). The context can be described by the first order non-homogeneous differential equation (Equation 4).

$$
\mathrm{dc} / \mathrm{dt}=\mathrm{k}(\mathrm{S}) *\left(\mathrm{c}(\mathrm{T})-\mathrm{c}_{\mathrm{s}}\right)
$$

where $\mathrm{k}(\mathrm{S})$ is the reaction rate constant of this process depending on the level of supersaturation $\mathrm{S}$ of the erythritol solutions, $\mathrm{c}(\mathrm{T})$ is the concentration of the prepared erythritol solution depending on the temperature of preparation, and $c_{s}$ is the concentration of saturation at the storage temperature. Therefore, the storage temperature also influences the supersaturation value. In the experiments described in this section the storage temperature was $5^{\circ} \mathrm{C}$ and thus, $\mathrm{c}_{\mathrm{s}}$ was $33 \mathrm{~g}$ per $100 \mathrm{~g}$ water according to section 3.1 . 
Equation 4 can be integrated to receive equation 5 as stated below:

$$
\mathrm{k}(\mathrm{S})=\frac{\log \left(\left(\mathrm{c}\left(\mathrm{t}_{\mathrm{i}}\right)-\mathrm{c}_{\mathrm{S}}\right) /\left(\mathrm{c}\left(\mathrm{t}_{\mathrm{i}+1}\right)-\mathrm{c}_{\mathrm{S}}\right)\right)}{\mathrm{t}_{\mathrm{i}+1}-\mathrm{t}_{\mathrm{i}}}
$$

where $\mathrm{c}_{\mathrm{s}}$ is the concentration of saturation at a storage temperature of $5^{\circ} \mathrm{C}, \mathrm{c}\left(\mathrm{t}_{\mathrm{i}}\right)$ is the concentration of solute erythritol at time $t_{i}$ and $c\left(t_{i+1}\right)$ is the concentration of solute erythritol at time $t_{i+1}$. According to equation 5 the concentration of dissolved erythritol at $t_{i}$ and $t_{i+1}$ related to the concentration of saturation $c_{s}$ at $5^{\circ} \mathrm{C}$ $\left(\log \left(\left(\mathrm{c}\left(\mathrm{t}_{\mathrm{i}}\right)-\mathrm{c}_{\mathrm{s}}\right) /\left(\mathrm{c}\left(\mathrm{t}_{\mathrm{i}+1}\right)-\mathrm{c}_{\mathrm{s}}\right)\right)\right)$ was plotted against the storage times and resulted in a straight line (Figure 2$)$. The obtained coefficient of determination $\left(\mathrm{R}^{2}\right)$ was 0.946 . The slope of this line representing the reaction rate constant $\mathrm{k}$ for the supersaturation level of 1.1 was $0.234\left(\mathrm{~h}^{-1}\right)$.

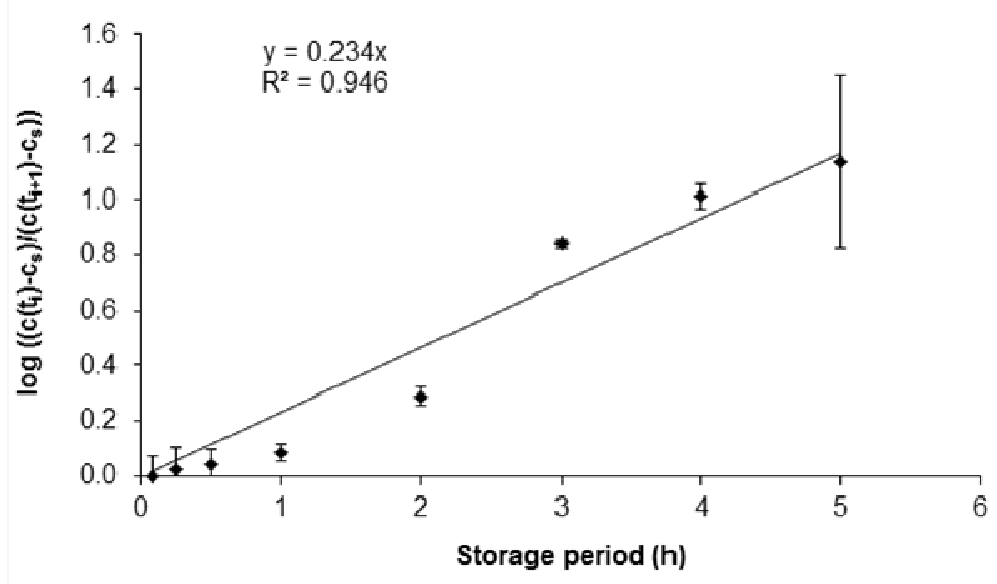

Figure 2. Kinetic of erythritol crystallization from the solution containing $69 \mathrm{~g}$ erythritol per $100 \mathrm{~g}$ water (supersaturation $=1.1)$

These results seemed to be influenced by the diffusion of erythritol to the surface of the growing crystals because a linear crystal growth over different storage times was obtained instead of immediate crystallization. Similar results were found for sucrose crystallization by Van Hook $(1944,1945)$. He stated that the crystallization process seemed to be driven by a sequence of various processes, namely the formation of interfaces between solvent and solute, aggregation of seed crystals, crystal growth and the formation of equilibrium between soluble and crystalline matters. All of them are known to be limited by diffusion. Additional experiments were performed using several solutions at different supersaturation levels and different storage temperatures in order to get a deeper insight into erythritol crystallization (section 3.3 and 3.4).

\subsection{Influences of Different Supersaturation Levels on Crystallization}

As described in section 2.2.2, solutions containing $33 \mathrm{~g}$ erythritol per $100 \mathrm{~g}$ water to $150 \mathrm{~g}$ erythritol per $100 \mathrm{~g}$ water, respectively, were prepared at different temperatures in order to produce saturated solutions. Subsequently, these solutions were immediately placed in the storage room which was tempered to $5^{\circ} \mathrm{C}$ and stored for a maximum of $168 \mathrm{~h}$ ( 1 week) to determine the course of erythritol crystallization as shown for $69 \mathrm{~g}$ erythritol per $100 \mathrm{~g}$ water previously (section 3.2). The crystallization values of these solutions were determined after $0.5,1,2$, 24, and $168 \mathrm{~h}$ (1 week), respectively. The results shown in Figure 3 indicate that the crystallization of erythritol depends strongly on the concentration of these solutions, and therefore, their supersaturation levels $\mathrm{S}$.

It was shown that the crystallization values after a storage time of $0.5 \mathrm{~h}$ increased with increasing erythritol concentration. These findings are in good agreement with the findings of Twieg and Nickerson (1968) who reported that the crystallization of lactose increased with increasing supersaturation. After $0.5 \mathrm{~h}$ no crystallization occurred during the storage of erythritol solutions with supersaturation levels of $0,0.4,0.6$ and 1.1, respectively. Erythritol solutions with supersaturation levels of 1.7, 2.4, and 3.5 exhibited crystallization values of $20 \%, 45 \%$, and $57 \%$, respectively, after $0.5 \mathrm{~h}$ of storage. The progress of crystallization is nearly linear until a maximum crystallization value is reached as already described for Figure 1. After storage for $24 \mathrm{~h}$ and $168 \mathrm{~h}$, respectively, no further crystallization occurred and equilibrium between soluble and crystalline erythritol was obtained. Thus, 
the maximum crystallization values of $30 \%, 43 \%, 47 \%, 67 \%, 75 \%$, and $80 \%$ (Figure 3 ) depended on the supersaturation levels of erythritol.

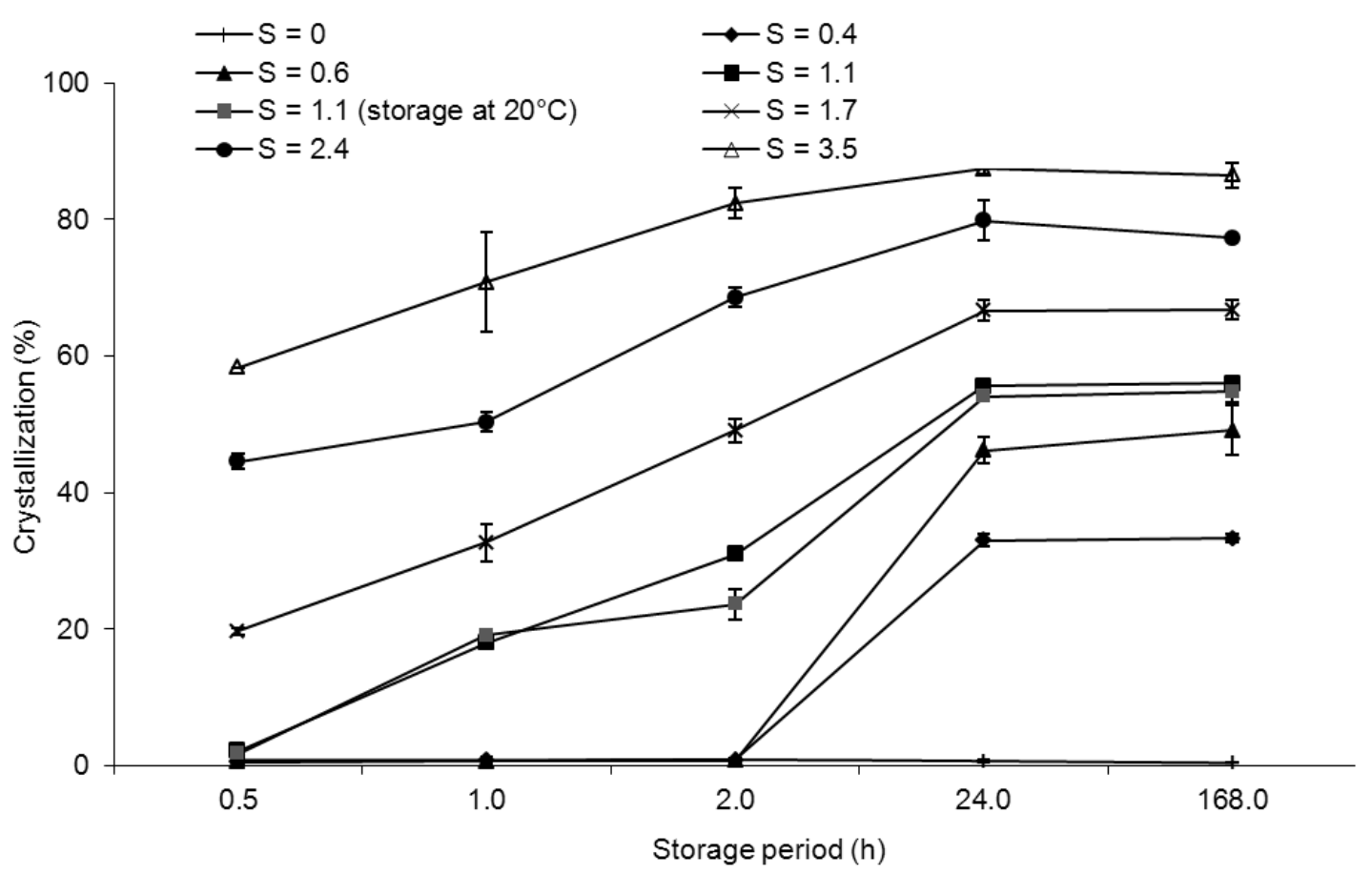

Figure 3. Crystallization of erythritol at different supersaturation levels; solutions at $\mathrm{S}=0,0.4,0.6,1.1,1.7,2.4$,

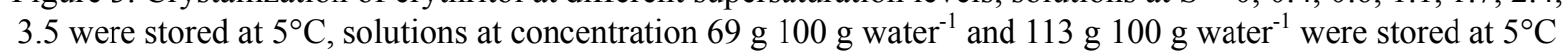
and $20^{\circ} \mathrm{C}$, respectively, resulting in the same $\mathrm{S}=1.1$, thereby the solution at concentration of $69 \mathrm{~g} 100 \mathrm{~g} \mathrm{water}^{-1}$ is labeled $(\mathrm{S}=1.1)$ and the solution at concentration of $113 \mathrm{~g} 100 \mathrm{~g} \mathrm{water}^{-1}$ is labeled $\mathrm{S}=1.1$ (storage at $20^{\circ} \mathrm{C}$ )

These values matched the predicted values based on a mass balance. The higher the supersaturation level the higher was the maximum crystallization of erythritol after $24 \mathrm{~h}$. After crystallization, the soluble erythritol amounted to $33 \mathrm{~g}$ per $100 \mathrm{~g}$ water, which is in good agreement with the concentration of saturation $c_{s}$ at $5^{\circ} \mathrm{C}$ as already described previously. These findings support the hypothesis that the concentration of saturation of erythritol at the respective storage temperature significantly influences the values of crystallization. Furthermore, after $168 \mathrm{~h}$ of storage no crystallization was observed for the solution containing $33 \mathrm{~g}$ erythritol per $100 \mathrm{~g}$ water having no supersaturation at $5^{\circ} \mathrm{C}$.

Similar results were found very early for the crystallization process of lactose hydrate from supersaturated solutions (Hudson, 1904). For pure lactose hydrate solutions the concentration of soluble lactose hydrate after crystallization represented the saturation of lactose hydrate at that particular temperature (Hudson, 1904).

The crystallization rate constants $\mathrm{k}$ for the studied supersaturation levels from $\mathrm{S}=0$ to $\mathrm{S}=3.5$ were determined by plotting the concentrations $\mathrm{c}\left(\mathrm{t}_{\mathrm{i}}\right)$ and $\mathrm{c}\left(\mathrm{t}_{\mathrm{i}+1}\right)$ against the time (as shown in Figure 2) and are listed in Table 1.

As shown in Table 1, the crystallization rate constant $\mathrm{k}$ correlated with the level of supersaturation of erythritol, meaning that with increased supersaturation the crystallization rate constant increased considerably. These results are in good agreement with the data reported by Twieg and Nickerson (1968) for lactose and by Van Hook (1944) for sucrose crystallization. The crystallization rate constants in both studies increased with increasing supersaturation. Therefore, not only diffusional effects are responsible for the crystallization of erythritol, but also temperature, supersaturation, and potentially surface area of the crystals have an important impact on the crystallization. 
Table 1. Supersaturation levels of erythritol solutions and corresponding crystallization rate constants

\begin{tabular}{ccc}
\hline $\begin{array}{c}\text { Concentration of erythritol } \\
\text { in water } \\
\mathrm{c}(\mathrm{T})\left(\mathrm{g} 100 \mathrm{~g} \mathrm{water}^{-1}\right)\end{array}$ & $\begin{array}{c}\text { Supersaturation level S } \\
\text { 33 }\end{array}$ & $\begin{array}{c}\text { Crystallization rate } \\
\text { constant } \\
\mathrm{k}\left(\mathrm{h}^{-1}\right)\end{array}$ \\
\hline 5 & 0 & no crystallization \\
54 & 0.4 & 0.080 \\
69 & 0.6 & 0.090 \\
89 & 1.1 & 0.209 \\
113 & 1.7 & 0.944 \\
150 & 2.4 & 1.557 \\
& 3.5 & 5.076
\end{tabular}

Generally, the crystallization rate constant fitted to an exponential gain with increasing supersaturation. Thus, the following equation (6) can be assumed for the dependency of the crystallization rate constant from the level of supersaturation with a coefficient of determination $\mathrm{R}^{2}$ of 0.97 (Figure 4):

$$
\mathrm{k}\left(\mathrm{h}^{-1}\right)=0.049 * \mathrm{e}^{1.4^{*} \mathrm{~S}}
$$

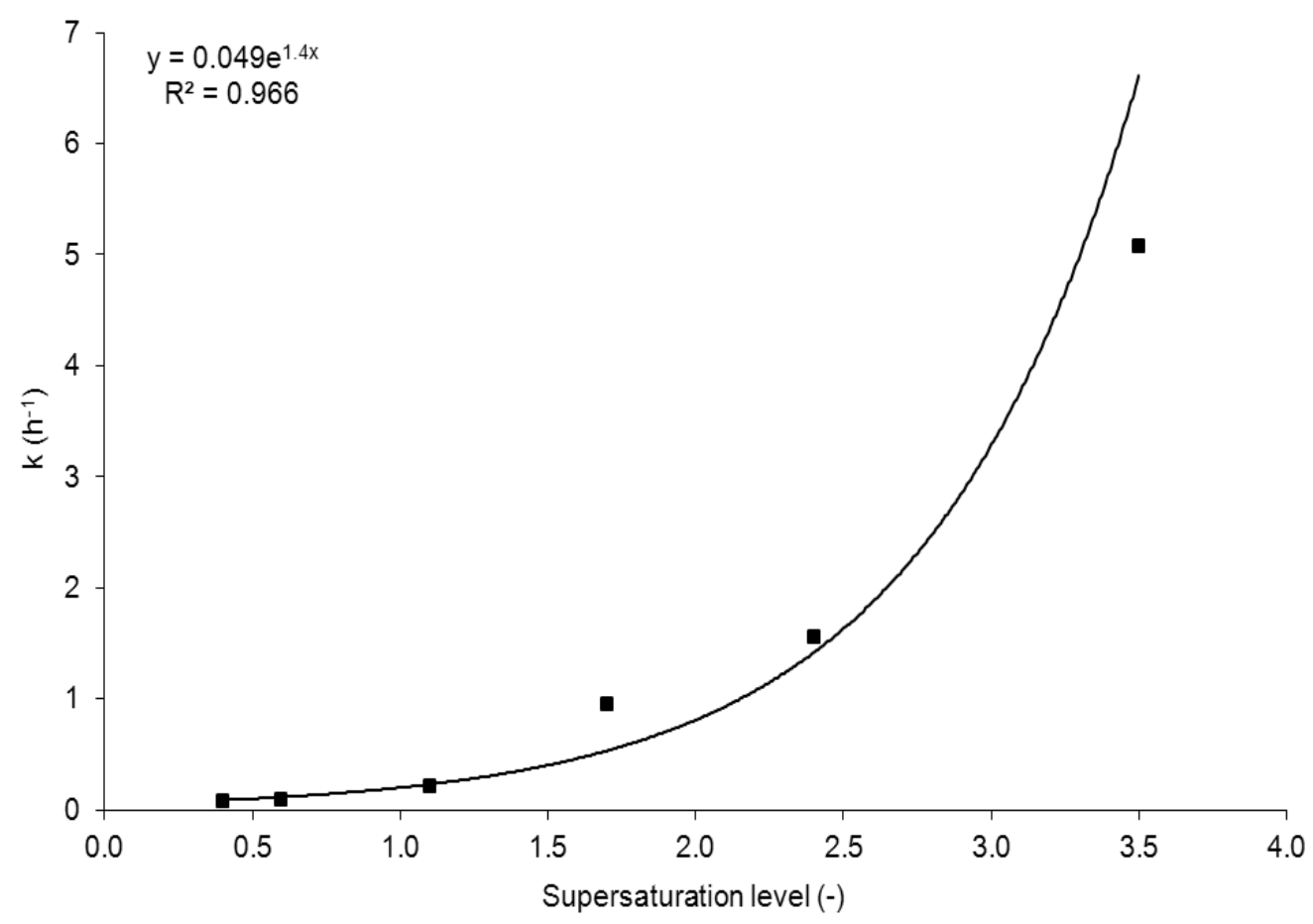

Figure 4. Dependence of supersaturation level of aqueous solutions on reaction rate constant $(\mathrm{k})$ of erythritol crystallization

Subsequently, solutions containing $113 \mathrm{~g}$ erythritol per $100 \mathrm{~g}$ water were prepared at $50^{\circ} \mathrm{C}$ and stored at two different temperatures $\left(5^{\circ} \mathrm{C}\right.$ and $\left.20^{\circ} \mathrm{C}\right)$ representing supersaturation levels 2.4 and 1.1, respectively. Using this experimental setup the influence of two different storage temperatures, and therefore, supersaturation level should be investigated. The results are shown in Figure 3 among other results of the influence of supersaturation levels on the crystallization. Thereby the crystallization values of the solution that was stored at $20^{\circ} \mathrm{C}$ are labeled with $\mathrm{S}=1.1$ (storage at $20^{\circ} \mathrm{C}$ ).

As it was expected, the progress of crystallization was faster for higher $(\mathrm{S}=2.4)$ than for lower $(\mathrm{S}=1.1$ (storage 
at $\left.20^{\circ} \mathrm{C}\right)$ ) supersaturation values. In accordance, the crystallization values obtained at $5^{\circ} \mathrm{C}(\mathrm{S}=2.4)$ are higher than the crystallization values of solutions stored at $20^{\circ} \mathrm{C}\left(\mathrm{S}=1.1\right.$ (storage at $20^{\circ} \mathrm{C}$ )) for all investigated storage times. A similar course of crystallization was obtained for equal supersaturation levels $(\mathrm{S}=1.1$ and $\mathrm{S}=1.1$ (storage at $20^{\circ} \mathrm{C}$ )) at different storage temperatures. Therefore, the crystallization depended on the supersaturation, but was independent of the storage temperatures.

\subsection{Effect of Cooling Rate on Crystallization and Crystal Morphology}

In order to understand the influence of the cooling rate on the crystallization of erythritol and the crystal growth process, two erythritol solutions both saturated at a temperature of $60^{\circ} \mathrm{C}(\mathrm{S}=3.5)$ were rapidly and slowly cooled to $5^{\circ} \mathrm{C}$ as described detailed in section 2.2. Significant differences $(\mathrm{p}<0.05)$ between the crystallization values of these solutions were not determined (data not shown). However, the cooling rate of the solutions and the temperature, at which the crystallization began, influenced crystal size, crystal morphology and crystal shape. These results were confirmed by the analysis of microscopic images as shown in Figures $5 \mathrm{a}$ and $5 \mathrm{~b}$. Similar results were reported previously for sucrose crystallization by Guimaraes, Sa, Bento and Rocha (1995). However, for a distinct correlation of the temperature at which the crystallization starts and final crystal size, morphology and shape, the crystallization should be followed by X-ray spectroscopy, atomic force spectroscopy or confocal laser scanning microscopy.

As shown in Figures $5 \mathrm{a}$ and $5 \mathrm{~b}$, the crystal size was significantly higher for slowly compared to rapidly cooled solutions. Furthermore, different crystal shapes were obvious for the different cooling rates.

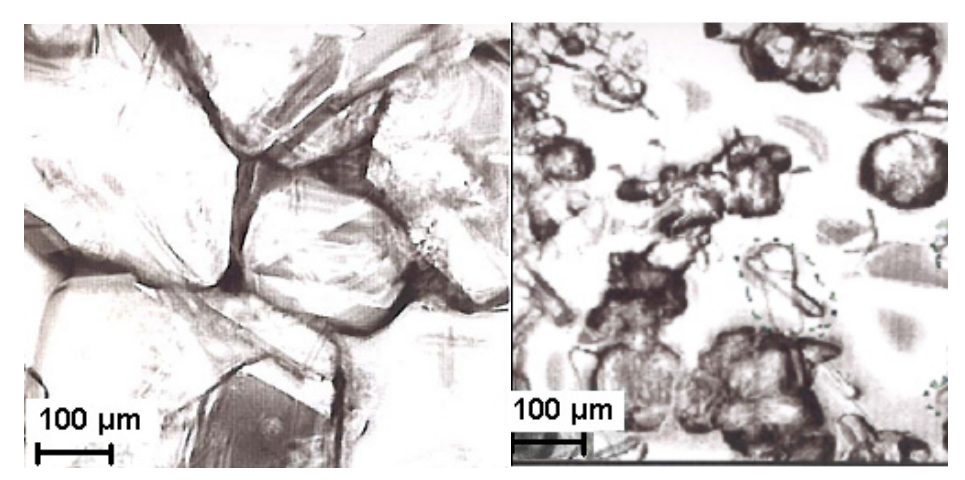

a)

b)

Figure 5. Photomicrographs of erythritol crystals observed from erythritol solution

(150 g erythritol $100 \mathrm{~g}_{\text {water }}{ }^{-1}$, supersaturation 3.5) after $24 \mathrm{~h}$ storage time at $5^{\circ} \mathrm{C}$ : a) slow cooling at rate of $1 \mathrm{~K} \mathrm{~min}^{-1}$; b) rapid cooling at rate of $5.5 \mathrm{~K} \mathrm{~min}^{-1}$

As shown in Figure 5a, slow cooling rates corresponded to the formation of large and compact erythritol crystals with an average length of $200-400 \mu \mathrm{m}$ and a nearly tetragonal structure also reported by Kasumi (1995). After rapid cooling a great number of small-sized erythritol crystals with an average length of $50-100 \mu \mathrm{m}$ were formed (Figure 5b). These findings are in good agreement with previous research studies on sucrose crystallization (Guimaraes et al., 1995; Pantaraks \& Flood, 2005; Promraksa, Flood, \& Schneider, 2009; Van Hook, 1944), which showed that the crystal surface becomes rougher depending on the crystallization process. Van Hook (1944) also stated that the size distribution of crystals depends on the supersaturation of the solutions, which is in good accordance to our findings.

\section{Conclusions and Outlook}

Prior to investigations of the erythritol crystallization under industry-like conditions, the course of erythritol crystallization was investigated in pure aqueous solutions using a simple gravimetric method. A crystallization process, which essentially follows the saturation line, was assumed for erythritol due to the dependency of crystallization on supersaturation levels of the particular solutions. Several lines of evidence indicate that the growth rate of erythritol crystals from pure solutions is determined by a first-order reaction, which means that the crystallization rate constant depends only on the erythritol concentration and therefore, on the level of supersaturation. Furthermore, the cooling rate of supersaturated erythritol solutions influenced the crystal shape of pure erythritol, but not the growth rate. At low cooling rates, crystals with significantly greater sizes were 
obtained. However, no influences on the amount of erythritol crystals became obvious. These results about the influence of various extrinsic (temperature and cooling rate) as well as intrinsic (supersaturation level) parameters are especially important for further detailed clarification of crystal formation and crystallization mechanisms. For these investigations following methods are considered to be possible: polarized light thermal microscopy, X-ray powder diffraction, atomic force spectroscopy, confocal laser scanning microscopy, and Fourier transformed infrared spectroscopy. Once the exact crystallization mechanism of erythritol on molecular scale is clarified, the influence of various additives and impurities on the erythritol crystallization at the conditions simulating the actual production process could be further investigated. This knowledge will help to pave a way for the development and optimization of the erythritol production process to obtain products with various crystal size distributions depending on individual requirements of the food industry.

\section{Acknowledgements}

This research is financially supported by a grant from the german Federal Ministry of Economics and Technology (BMWi; InnoNet project 16IN0687). The authors are responsible for the content of this publication.

\section{References}

Abdel-Rahman, E. A., Schick, R., \& Kurz, T. (2007). Influence of dextran on sucrose crystallization. Zuckerindustrie, 132, 453-460.

Abdel-Rahman, E. A., Smejkal, Q., Schick, R., Ei-Syiad, S., \& Kurz, T. (2008). Influence of dextran concentrations and molecular fractions on the rate of sucrose crystallization in pure sucrose solutions. Journal of Food Engeneering, 84, 501-508. http://dx.doi.org/10.1016/j.jfoodeng.2007.06.014

Bhandari, B. R., \& Hartel, R. W. (2002). Co-crystallization of sucrose at high concentration in the presence of glucose and fructose. Journal of Food Science, 67, 1797-1802. http://dx.doi.org/10.1111/j.1365-2621.2002.tb08725.x.

Campbell, A. N., \& Campbell, A. J. R. (1937). The velocity of crystallization from supersaturated solutions. Transactions of the Faraday Society, 33, 299-308. http://dx.doi.org/10.1039/tf9373300299

Guimaraes, L., Sa, S., Bento, L. S. M., \& Rocha, F. (1995). Investigation of crystal growth in a laboratory fluidized-bed. International Sugar Journal, 97, 199-204.

Hudson, C. S. (1904). The hydration of milk sugar in solution. Journal of the American Chemical Society, 26, 1065-1082.

Kasumi, T. (1995). Fermentative production of polyols and utilization for food and other products in Japan. Jarq-Japan Agricultural Research Quarterly, 29, 49-55.

Lopes Jesus, A. J., Nunes, S. C. C., Ramos Silva, M., Matos Beja, A., \& Redinha, J. S. (2010). Erythritol: crystal growth from the melt. International Journal of Pharmaceutics, 388, 129-135. http://dx.doi.org/10.1016/j.ijpharm.2009.12.043

Martins, P. M., Ferreira, A., Polanco, S., Rocha, F., Damas, A. M., \& Rein, P. (2009). Unsteady-state transfer of impurities during crystal growth of sucrose in sugarcane solutions. Journal of Crystal Growth, 311, 3841-3848. http://dx.doi.org/10.1016/j.jcrysgro.2009.05.021

Martins, P. M., Rocha, F., \& Rein, P. (2005). Modeling sucrose evaporative crystallization. Part 1. Vacuum pan monitoring by mass balance and image analysis methods. Industrial \& Engineering Chemistry Research, 44, 8858-8864. http://dx.doi.org/10.1021/ie050639h

Ohmori, S., Ohno, Y., Makino, T., \& Kashira, T. (2004). Characteristics of erythritol and formulation of a novel coating with erythritol termed thin-layer sugarless coating. International Journal of Pharmaceutics, 278, 447-457. http://dx.doi.org/10.1016/j.ijpharm.2004.04.004

Pantaraks, P., \& Flood, A. E. (2005). Effect of growth rate history on current crystal growth: A second look at surface effects on crystal growth rates. Crystal Growth \& Design, 5, 365-371. http://dx.doi.org/10.1021/cg049863k

Perko, R., \& DeCock, P. (2006). Erythritol. In J. R. Mitchel (Ed.), Sweeteners and Sugar Alternatives in Food Technology (pp. 151-176). Oxford, UK: Blackwell Publishing.

Promraksa, A., Flood, A. E., \& Schneider, P. A. (2009). Measurements and analysis of the dextran partition coefficient in sucrose crystallization. Journal of Crystal Growth, 311, 3667-3673. http://dx.doi.org/10.1016/j.jcrysgro.2009.04.042 
Röper, H., \& Goossens, J. (1993). Erythritol, a new raw material for food and non-food applications. Starch/Staerke, 45, 400-405. http://dx.doi.org/10.1002/star.19930451107

Schiweck, H., Clarke, M., \& Pollach, G. (2007). Sugar. In Ullmann's Encyclopedia of Industrial Chemistry (pp. 1-74). http://dx.doi.org/10.1002/14356007.a25_345.pub2

Trgo, C., Koxholt, M., \& Kessler, H. G. (1999). Effect of freezing point and texture regulating parameters on the initial ice crystal growth in ice cream. Journal of Dairy Science, 82, 460-465.

Twieg, W. C., \& Nickerson, T. A. (1968). Kinetics of lactose crystallization. Journal of Dairy Science, 51, $1720-1724$.

Van Hook, A. (1944). Kinetics of sucrose crystallization, pure sucrose solutions. Industrial and Engineering Chemistry, 36, 1042-1047.

Van Hook, A. (1945). Kinetics of sucrose crystallization, mechanism of reaction. Industrial and Engineering Chemistry, 37, 782-785.

Yoon, J. W., Jeon, E. J., Jung, I. H., Min, M. J., Lee, H. Y., Kim, M. J., ... Moon, T. W. (2003). Maltosyl-erythritol, a major transglycosylation product of erythritol by Bacillus stearothermophilus maltogenic amylase. Bioscience, Biotechnology, and Biochemistry, 67, 525-531. 